\title{
Poemas da Priapéia Latina
}

\author{
João Angelo Oliva Neto
}

1

Leitor dos versos lúbricos de um canto rude,

do pudor que convém ao Lácio esquece-te;

não mora neste templo a irmã de Febo, ou Vesta.

e a deusa que do pai nasceu, da testa,

as, rubro, o guarda dos jardins, de membro enorme,

que roupa nas virilhas nunca veste:

ou leva o manto à parte que cobrir se deve,

ou co' estes olhos com que a vês lê mais.

9

Por que em mim não tem veste a parte obscena, indagas?

Indaga se algum deus seus dardos cobre:

às claras o senhor do céu detém seu raio,

não se oculta o tridente ao deus das águas;

nem Marte esconde aquela espada com que é bravo

nem Palas guarda a lança em dobras tépidas.

Portando setas de ouro Febo acaso cora?

Diana sói levar, esconsa, a aljava?

E Hércules cobre a massa da nodosa clava?

O deus alado vela o caduceu?

Quem viu Baco estender no grácil tirso as vestes?

E quem, Amor, te viu de rosto oculto?

Não seja crime que meu pau se mostre sempre:

que se esta lança falta, eu sou inerme. 
NETO, João Angelo Oliva. Poemas da Priapéia Latina.

54

Se escreveres E D e no meio uma barra,

verás pintado quem te quer varar.

68

Se, rústico, pareço ter inculta fala,

perdão!, não junto livros, junto frutos.

Mas rude embora, à força eu ouço meu senhor

a ler, e uns termos aprendi de Homero:

p'ra nós o que é caralho chama de karákalon

e o que chamamos cu chama de cúleon.

Se merdaléon é aquilo que não tem limpeza,

é merdaleu o pinto dos que enrabam.

Mais!: se a buceta Argiva não quisesse um pau

Troiano, não lerias a epopéia.

Não fosse tão famoso o pinto de Agamêmnon,

Crises nada teria a reclamar.

mesmo pau tirou do amigo a doce amante:

sendo de Aquiles, quis que fosse sua,

e um triste canto o herói cantou à Peletrônia

cítara, estando teso mais que a cítara.

$\mathrm{Na}$ ira então começa a llíada famosa

foi o princípio do sagrado canto.

outro conta a errância do falaz Ulisses

e, a bem dizer, tesão foi que o moveu:

lemos de uma raiz que gera flor dourada que, embora moly a chamem, era um pau;

lemos que Circe, que a Atlantíade Calipso

quiseram grandes dotes ver de Ulisses.

Depois, ao ver que mal cobriu seu membro um espesso

ramo, a filha de Alcínoo se espantou.

Mas volta o herói à velha esposa só pensando,

Penélope, na tua bocetinha,

e mesmo casta já fazias teus banquetes 
por ter de fodedores cheia a casa,

e por saberes qual o mais valente assim

falaste aos pretendentes excitados:

"Ninguém mais duro pau ergueu que o meu Ulisses,

servindo-se de força ou de perícia.

Agora que ele é morto, ficai duros, quero

saber quem é que é homem como aquele."

E eu poderia assim te dar prazer, Penélope,

mas então não me tinham feito ainda.

1

Carminis incompti lusus lecture procaces,

conveniens Latio pone supercilium.

Non soror hoc habitat Phoebi, non Vesta sacello,

nec qua de patrio vertice nata dea est,

sed ruber hortorum custos, membrosior aequo,

qui tectum nullis uestibus inguen habet.

Aut igitur tunicam parti praetende tegendae, aut quibus hanc oculis aspicis, ista lege.

9

Cur obscena mihi pars sit sine veste requiris? quaere tegat nullus cur sua tela deus.

Fulmen habens mundi dominus tenet illud aperte; nec datur aequoreo fuscina tecta deo.

Nec Mauors illum, per quem ualet, occulit ensem; nec latet in tepido Palladis hasta sinu.

Num pudet auratas Phoebum portare sagittas?

Clamne solet pharetram ferre Dianam suam?

Num tegit Alcides nodosae robora clauae?

Sub tunica virgam num deus ales habet? 
NETO, João Angelo Oliva. Poemas da Priapéia Latina.

Quis Bacchum gracili vestem praetendere thyrso.

Quis te celata cum face vidit, Amor?

$\mathrm{Nec}$ mihi sit crimen quod mentula semper aperta est: hoc mihi si telum desit, inermis ero.

54

ED si scribas temonemque insuper addas, qui medium uult te scindere pictus erit.

68

Rusticus indocte si quid dixisse videbor da veniam: libros non lego, poma lego.

Sed rudis hic dominum totiens audire legentem cogor Homereas edidique notas.

Psolen ille vocat quod nos psoloenta vocamus et quod nos culum, culeon ille vocat.

Merdaleon certe si res non munda vocatur, et pediconum mentula merdalea est.

Quid? Nisi Taenario placuisset Troica cunno mentula, quod caneret, non habuisset opus

Mentula Tantalidae bene si non nota fuisset, nil senior Chryses quod quereretur erat.

Haec eadem socium tenera spoliauit amica, quaeque erat Aecidae, maluit esse suam.

Ille Pelethroniam cecinit miserabile carmen

ad citharam; cithara tensior ipse sua.

Nobilis hinc nata nempe incipit llias ira, principium sacri carminis illa fuit.

Altera materia est error fallentis Vlixei; si verum quaeras, hunc quoque mouit amor.

Hic legitur radix, de qua flos aurea exit, quem cum moly uocat, mentula fuit. 
Hic legimus Circen Atlantiadem Calypson grandia Duilichii uasa petisse viri.

Huius et Alcinoi mirata est filia membrum

frondenti ramo vix potuisse tegi.

Ad vetulam tamen ille suam properabat et omnis mens erat in cunno, Penelope, tuo:

quae si casta manes, ut iam convivia uisas utque fututorum sit tua plena domus.

E quibus ur scires quicumque valentior esset, haec es ad arrectos verba locuta procos: "nemo meo melius neruum tendebat Vlixe, sive illi laterum sive erat artis opus.

Qui quoniam periit, uos nunc intendite, qualem esse virum sciero, uir sit ut ille meus." Hac ego, Penelope, potui tibi lege placere, illo sed nondum tempore factus eram. 